\title{
The Capability Maturity Model as an Industrial Process Improvement Model
}

\author{
Daniel A. Doss ${ }^{1, *}$, Rebecca Goza ${ }^{2}$, Raymond Tesiero ${ }^{1}$, Balakrishna Gokaraju ${ }^{1}$, David H. McElreath ${ }^{3}$ \\ ${ }^{1}$ College of Business and Technology, University of West Alabama, United States \\ ${ }^{2}$ College of Business, University of Central Oklahoma, United States \\ ${ }^{3}$ College of Applied Sciences, University of Mississippi, United States
}

Copyright $\bigcirc 2017$ by authors, all rights reserved. Authors agree that this article remains permanently open access under the terms of the Creative Commons Attribution License 4.0 International License

\begin{abstract}
This study examined the potential of adapting the software Capability Maturity Model as a process improvement paradigm within the context of industrial process improvement. Traditional methods of process improvement incorporate some facets of Total Quality Management (TQM), business process improvement (BPI), business process reengineering (BPR), business process management (BPM), benchmarking, regulation, legislation, Six Sigma, and standards. Hypothesis testing showed two statistically significant outcomes regarding the first and the fifth maturity levels reflecting ad hoc processes and optimized processes, respectively.
\end{abstract}

Keywords Capability Maturity Model, Industrial Process, Process Improvement, Quality Management

\section{Introduction}

Organizational processes generate some form of value and effectiveness. Typically, their value may be examined from a variety of perspectives: mapping, quantification, accountability, certification, integration, intelligence, and compliance [28]. Regardless of perspective, the optimizing of processes contributes toward enhancing both effectiveness and efficiency organizationally [1]. Process optimization may affect the long-term, strategic competitiveness of organizations over periods encompassing an average of five or more years [2].

Numerous methods exist for optimizing and improving processes among organizational settings. Among these methods are traditional forms of business process improvement, business process management, business process reengineering, business process change, Total Quality Management, Lean methods, policy, Six Sigma, and proprietary paradigms $[3,4,5,6,7,8,9,10,11,12,13,46]$. Although these paradigms may provide some amount of process improvements thereby enhancing effectiveness and efficiency, they do not address improvement from the perspective of process maturity. Essentially, the traditional forms of improvement lack the characteristics of progressively and sequentially maturity processes through time as an underlying framework within their respective, foundational tenets.

Process improvements have generated a variety of benefits for organizations seeking optimized work environments. For instance, some paradigms generate cost savings whereas others facilitate avoiding certain costs [14]. Financial amounts saved by such improvement investments may be substantial depending upon organizational size, and may range into millions of dollars [15]. Savings of time may also result from process improvement [11]. Other aspects of beneficence and organizational value include increased accountability, reliability improvements, compliance with regulations, bolstered security and safety, and less waste [16].

Famous and notable organizations have been lauded as industry successes for their process improvement and quality initiatives. For instance, FedEx among the first in its industry to receive globally ISO 9001 certification and received the Malcolm Baldrige National Quality Award [17]. After investing approximately $\$ 500,000$ in an improvement initiative addressing project rework, Raytheon experienced rework savings of approximately $\$ 4.48$ million during the initial year of implementation [18]. The fifth year of implementation showed savings of approximately $\$ 15.8$ million [18]. Another example involves improving managing development costs at Tenzer-Spring Dynamics. In this instance, after two years of implementing improvement initiatives, the organization exhibited reductions of "project overruns" of approximately $\$ 3$ million thereby representing lowered development costs of approximately $55 \%$ [18, p. 24]. Hughes Aircraft, after an initial investment of approximately $\$ 445,000$, experienced cost savings of approximately $\$ 2$ million annually after incorporating initiatives to foster 
improvements in areas of "training, peer reviews, Process Group formation, and quality assurance" [18, p. 25]. Boeing Corporation experienced cycle time improvements of about $50 \%$ and reduced its amounts of rework by approximately $31 \%$ following the implementation of an improvement initiative [18]. Within three years of implementing an improvement initiative, Schlumberger experienced an ability to provide on-time delivery time of approximately $99 \%$ for its customers [18]. Similarly, after implementing an improvement initiative, Behrben International experienced on-time delivery of for its software products of approximately " $94 \%$ in less than 19 months" [18, p. 25]. Hewlett-Packard experienced reductions of software code defects by approximately $51 \%$ couple with a $57 \%$ productivity increase [18]. Although each of these cases generated improvements for its respective work settings, none of them incorporated maturity of process as the foundational paradigm and philosophical basis among improvement initiatives.

Such dramatic improvements and cost reductions are not uncommon among organizations that proactively implement some form of process improvement paradigms. The traditional paradigms of organizational and quality improvement are capable of generating substantial improvement and value organizationally. Modern corporations must compete efficiently and effectively within the global economy. Achieving and maintaining organizational efficiency and effectiveness may be enhanced through various quality management pursuits [19]. Typically, examples of such endeavors include traditional paradigms, such as Total Quality Management (TQM), business process improvement (BPI), business process reengineering (BPR), business process management (BPM), benchmarking, regulation, legislation, Six Sigma, and standards [20, 21, 22]. Despite the benefits that may be gleaned from any uses of traditional quality paradigms, none approach process improvement solely from the perspective of process maturity as its foundational basis [20].

\subsection{Theoretical Framework}

Despite the lack of traditional improvement and quality paradigms whose fundamental philosophies and tenets are absent the incorporating of maturity of process as a guiding cornerstone, a model exists within the software domain whose basis does reflect process maturity as its fundamental basis. This model is the Capability Maturity Model (CMM). It consists of a five-phase framework whereby processes may be matured progressively through time [23]. These phases consist of the following: 1) initial - ad hoc, random, and poor control; 2) repeatable - basic management and repeatability; 3) defined - processes are understood, well-defined, and documented; 4) managed - processes are controlled and quantitatively analyzed; and 5) optimizing processes are optimal and are subject to continual improvement [23]. Thus, the CMM represents the underlying theoretical framework for this study.

\subsection{Conceptual Framework}

Using its five-stage framework as a basis, derivatives of the CMM have been applied in a variety of unrelated areas. Examples of unaffiliated domains wherein derivative CMM frameworks exist include police organizations, human capital, finance, industry, security, education, quality, project management, software testing, and environmental management [20, 24, 25, 26, 27, 28, 29, 30, 31, 32, 33]. Such derivatives show the potentials of CMM applications and portability among disciplines and domains that are not reflective of its origins in the software industry. Given the presence of derivative CMM paradigms among unrelated applications, this study examines the potential of adapting the CMM framework within the context of industrial settings. Specifically, this study proposes and assesses quantitatively a derivative model deemed the industrial process maturity model (IPMM).

A financial management perspective of organizations necessitates considerations of optimizing performance operationally to better efficiency to improve production [34]. Among for-profit entities, the primary goal of any organizational financial management is the maximizing of shareholder wealth $[35,36,37]$. Resource optimization contributes to this goal of wealth accumulation through time $[38,39]$. Non-profit organizations seek to maximize and optimize revenue streams and cash flows [40]. The final stage of the maturity model framework represents a state of optimization among organizational processes [41]. Given these observations, the maturity model framework has the potential of contributing to the wealth maximization goal of financial management by optimizing organizational performance. Such optimized performance in the fifth maturity level may also benefit both organizational efficiency and enhance production. Thus, the proposed IPMM may have value for organizations attempting to achieve such optimization.

\subsection{Goals and Expectations}

Three foundational goals and expectations highlighted this research endeavor: 1) it was expected that this study would show CMM transferability within an industry unrelated to the software domain, 2) it was expected that this study would show that existing process improvement methods did not address issues of process maturity, and 3) it was expected that this research would show that existing industrial process environments did not conform to the CMM tenets and levels. Given the existence of CMM derivatives among unrelated domains and disciplines, a proposed CMM derivate for addressing the process improvement needs of industrial production was generated from the five-phase framework of the CMM fundamental architecture. Thus, this study investigated the potential of CMM adaptation and 
portability.

\section{Materials and Methods}

\subsection{Design and Stratification}

The research design and methodology for this study consisted of a national study that examined the potential of adapting the CMM as a process improvement paradigm within the context of industrial processes. The research methodology consisted of a cross-sectional research design wherein a Likert survey was used to collect perceptions of managers versus non-managers regarding their beliefs about processes within their respective work settings. This stratification was selected because it represents a dichotomy of views regarding the organizational setting - one from individuals who lead and guide the organization and the other from those who represent the backbone of the operational workforce of the organization. Approval for the study was granted by the Institutional Review Board before the study commenced.

\subsection{Population and Sample}

A population of 1,500 potential respondents was identified from national listings of organizations that required an emphasis regarding production and operation environments. Mailing addresses consisted of position titles, but not specific individuals. Random sampling was used to generate the sample via selection of every fifth candidate respondent from the population.

\subsection{Data Processing}

Data processing consisted of one-way, two-tailed analysis of variance (ANOVA) to investigate differences of perceptions concerning the stratification of managers versus non-managers. The significance level for hypothesis testing was 0.05 . The Omega-squared method was used to examine effect size for statistically significant outcomes.

\subsection{Survey Instrument}

The survey instrument consisted of three primary sections: 1) environmental characteristics, 2) improvement initiatives, and 3) demographic data. Survey items 1 through 10 examined various attributes of respondent working environments. Survey items 11 through 16 examined improvement initiatives among respondent working environments. Items 1 through 16 represented Likert-scale responses wherein the value of 1 represented strong disagreement, the value of 3 represented neutrality, and the value of 5 represented strong agreement. Survey items 17 through 23 amassed demographic data. Demographic inquiries consisted of respondent's job role, previous improvement initiatives, current improvement initiatives, quantity of personnel employed by the organization, competitive industry, percentage of personnel associated with process improvement, and geographic region of the employer.

\subsection{Correlation Analysis}

Investigation of survey item concept relationships was performed via the Pearson correlation coefficient method. The Pearson correlation analysis was used to examine the potential strength of relationship between the notion that grouping of processes by maturity level would improve the outcomes of production processes and the notion that improvement initiatives advocating process grouping by category. The Pearson correlation analysis was also used to investigate the potential strength of relationship between the notion that grouping of processes by maturity level would improve the outcomes of production processes and the notion that process maturity is a contributor to successful process output.

\subsection{Response Directionality}

Response directionality was assessed via analyses of the means for each of the survey questions. Ranges for response directionality are often subjective [42]. Regarding responses to the Likert scale, the following categories were used to perform means analyses: disagree if mean value $<2.5$; neutrality if $2.5 \leq$ mean value $\leq 3.5$; agree if mean value $>$ 3.5. Using such ranges provided a method of generating directional majorities among the reported responses.

\subsection{Bias Potential}

Examining the potential of bias regarding the survey was accomplished via the Chi-squared method. Using competitive industry as its basis, the potential of bias was examined via a consideration of the issued distribution of responses with respect to the characteristics of the returned surveys.

\subsection{Scope}

The scope of the study was constrained to examining only personnel perceptions regarding industrial processes in order to quantitatively assess the proposed IPMM. Thus, any other process type or consideration was beyond the scope of this study.

\section{Hypotheses and Correlations}

\subsection{Framework Hypotheses}

Null hypotheses corresponded to each maturity level of the CMM framework. Specifically, the null hypotheses were: 
$H_{0,1}:$ There is no difference in the opinions of managers versus non-managers regarding the notion that production processes may be defined as being ad-hoc or chaotic.

$H_{0,2}$ : There is no difference in the opinions of managers versus non-managers regarding the notion that production processes are disciplined and repeatable.

$H_{0,3}$ : There is no difference in the opinions of managers versus non-managers regarding the notion that production processes are standardized and consistent.

$H_{0,4}$ : There is no difference in the opinions of managers versus non-managers regarding the notion that production processes are predictable.

$H_{0,5}$ : There is no difference in the opinions of managers versus non-managers regarding the notion that production processes are continuously being evaluated for improvement.

\subsection{Bias}

The null hypothesis associated with examining the potential of bias within the study was:

$H_{0,6}$ : There is no difference in the distribution of received survey responses versus the expected distribution of the original survey.

\subsection{Correlation}

Potential strengths of relationships were examined regarding the notions:

1. Grouping of processes by maturity level would improve the outcomes of production processes versus improvement initiatives emphasizing process grouping by category.

2. Grouping of processes by maturity level would improve the outcomes of production processes versus process maturity being a contributor to successful process output.

\section{Findings}

\subsection{Responses}

The returned surveys represented a response rate of approximately $21.3 \%$. Approximately $62 \%$ of the respondents reported a managerial status whereas $38 \%$ reported a non-managerial status. Regarding respondent organizations, approximately $10.6 \%$ of the respondents reported an organizational size of between 1 and 100 personnel; $4.25 \%$ reported a size of between 101 and 1,000 personnel; $17 \%$ reported a size of between 1,001 and 5,000 personnel; $6.38 \%$ reported a size between 5,001 and 10,000; $31.9 \%$ reported a size between 10,001 and 50,000 personnel; and $29.7 \%$ reported a size that exceeded 50,000 personnel.

\subsection{Bias}

The Chi-square outcome, used to judge bias with respect to the returned versus expected response, showed an $X^{2}$ value of 217.8 (versus table value of 18.30) thereby suggesting the presence of industry bias. Competitive industry was used as the basis for Chi-square analysis.

\subsection{Historical Improvement and Quality Initiatives}

The survey queried the historical use of process improvement and quality paradigms within the organizational setting. Approximately $13 \%$ of the respondents reported no previous process improvement initiatives within their respective work settings, about $43 \%$ reported the previous use of Total Quality Management, 21\% reported the use of business process re-engineering, 30\% reported business process improvement, $9 \%$ reported business process management, $21.2 \%$ reported benchmarking, $17 \%$ reported Six-Sigma, 3\% reported regulation, and $2 \%$ reported ISO 9000) (or another form of ISO).

\subsection{Current Improvement and Quality Initiatives}

The survey also queried the current use of process improvement and quality paradigms within the work setting. Approximately $13 \%$ of the respondents reported that no current method existed within the workplace, about 23\% reported the use of Total Quality Management, approximately $13 \%$ reported the use of business process reengineering, about $19 \%$ reported the use of business process improvement, approximately $28 \%$ reported benchmarking, approximately $29.7 \%$ reported the use of Six Sigma, about $20 \%$ reported regulation, and the remaining $20 \%$ reported some form of ISO.

\subsection{Competitive Industries}

The survey examined the competitive industries of the respondents. The demographics representing competitive industries were: furniture/timber $(4.25 \%)$, petroleum/gas/oil $(2.12 \%)$, aerospace/aviation (4.25\%), electronics/technical $(6.38 \%)$, medical/healthcare products $(6.38 \%)$, agricultural products $(2.12 \%), \quad$ shipping/delivery $\quad(6.38 \%)$, fabrication/metal (6.38\%), government/defense (12.7\%), automotive (6.38\%), and other (42.5\%).

\subsection{Process Improvement Personnel}

Respondents identified the percentage quantities of personnel whom were responsible for process improvement within their respective organizations. Approximately $46.8 \%$ of the respondents indicated that between $0 \%$ and $20 \%$ of personnel were responsible for process improvement. About $19.1 \%$ of respondents indicated that between $21 \%$ and $40 \%$ of personnel had process improvement responsibility. About $12.7 \%$ of respondents reported that between $41 \%$ and $60 \%$ of personnel were responsible for process improvement. Approximately $12.7 \%$ of respondents indicated that 
between $61 \%$ and $80 \%$ of personnel were responsible for process improvement. The remaining $8.5 \%$ of respondents indicated that between $81 \%$ and $100 \%$ of personnel involved process improvement.

\subsection{Geography}

Geographic regions within the survey were identified as Pacific, Mountain, Central, Southeast, and Northeast. The Pacific region consisted of the states of Alaska, Washington, Oregon, California, Nevada, Hawaii, and Idaho. The Mountain region consisted of the states of Montana, Wyoming, Colorado, Utah, Arizona, and New Mexico. The Central region was comprised of North Dakota, South Dakota, Nebraska, Kansas, Oklahoma, Texas, Louisiana, Arkansas, Missouri, Illinois, and Wisconsin. The Southeast region represented the states of Mississippi, Alabama, Florida, Georgia, South Carolina, North Carolina, Tennessee, Kentucky, Virginia, West Virginia, and the District of Columbia. The Northeast region consisted of the states of Maine, Vermont, New Hampshire, Maryland, Rhode Island, Connecticut, New Jersey, Delaware, Pennsylvania, New York, Illinois, Ohio, and Michigan.

The responses showed respondent presences among all of the identified geographic regions. Approximately $21.2 \%$ of the respondents indicated their geographic location as the Pacific region, 17\% reported the Mountain region, $40.4 \%$ reported the Central region, $68 \%$ reported the Southeast region, and $29.7 \%$ reported the Northeast region.

\subsection{First Hypothesis}

The first question queried whether processes were defined as ad hoc or chaotic. The overall mean for the question was 2.39 , the standard deviation was 1.38 , and variance was 1.92 . In general, the cumulative mean showed disagreement with the notion. With respect to the individual groups, managers reported a mean value of 2.03 whereas non-managers reported a mean value of 3.29. In other words, managers showed disagreement whereas non-managers showed neutrality. The ANOVA hypothesis testing showed statistical significance $(p=.002, \alpha=.05)$. The corresponding Omega-squared effect size was 0.18 .

\subsection{Second Hypothesis}

The second question queried whether production processes were disciplined and repeatable. The overall mean for the question was 3.95, the standard deviation was 0.99 , and variance was 0.97 . In general, the cumulative mean showed neutrality. With respect to the individual groups, managers reported a mean value of 4.16 whereas non-managers reported a mean value of 3.64. Both groups showed agreement with the notion. The ANOVA hypothesis testing showed no statistical significance ( $p$ $=.076 ; \alpha=.05)$.

\subsection{Third Hypothesis}

The third question queried whether production processes were predictable. The overall mean for the question was 3.59 , the standard deviation was 1.09 , and the variance was 1.18. In general, the overall mean showed neutrality. With respect to the individual groups, managers reported a mean value of 3.70 whereas non-managers reported a mean value of 3.35. Basically, managers agreed with the notion whereas non-managers showed neutrality. The ANOVA hypothesis testing showed no statistical significance $(p=.029 ; \alpha=.05)$.

\subsection{Fourth Hypothesis}

The fourth question queried whether production processes were predictable. The overall mean for the question was 3.59 , the standard deviation was 1.02 , and the variance was 1.04. In general, the overall mean showed neutrality. With respect to the individual groups, managers reported a mean value of 3.73 whereas non-managers reported a mean value of 3.23. Basically, managers agreed with the notion whereas non-managers showed neutrality. The ANOVA hypothesis testing showed no statistical significance $(p=.10 ; \alpha=.05)$.

\subsection{Fifth Hypothesis}

The fifth question queried whether production processes were continuously evaluated for improvement. The overall question mean was 4.30, the standard deviation was 1.03 , and the variance was 1.07. In general, the cumulative mean showed agreement. With respect to the individual groups, managers reported a mean value of 4.53 whereas non-managers reported a mean value of 4.00. Basically, both managers and non-managers agreed with the notion. The ANOVA hypothesis testing showed statistical significance $(p=.01 ; \alpha=.05)$. The corresponding Omega-squared effect size was 0.18 .

\subsection{First Correlation}

The first correlation outcome showed little, if any, strength of relationship ( $r=-0.02177)$ between the notions grouping of processes by maturity level would improve the outcomes of production processes and improvement initiatives emphasizing process grouping by category.

\subsection{Second Correlation}

The second correlation outcome showed little, if any, strength of relationship ( $r=0.02191)$ between the notions grouping of processes by maturity level would improve the outcomes of production processes and process maturity being a contributor to successful process output. 


\section{Conclusions and Recommendations}

Two of the five hypothesis tests showed statistical significance. Respectively, these tests showed statistical significance regarding the initial phase (ad hoc processes) and the fifth phase (optimized processes) within the maturity framework. Given these outcomes, because two null hypotheses were rejected, the full portability of the maturity framework across domains was not shown via this research study.

This outcome may be considered with respect to the goals and expectations of the study. Within this study, because of the rejected hypotheses suggesting the lack of portability for the examined model, the goal expectation of showing transferability of the model to the unrelated domain of industrial processes was unsatisfied. However, the goal of showing that existing process improvement methods did not address issues of process maturity was satisfied given that respondents demonstrated no clear majority or preference favoring such as approach. The final goal of this study was to show that existing industrial process environments did not conform to the CMM tenets and levels. This goal was achieved because the respondents showed primarily lower-level process maturity attributes (e.g., ad hoc or defined processes), but did not indicate the presence of higher levels of the maturity level framework with respect to the queried work settings.

The study showed practically no relationship between personnel beliefs about process maturity versus process outcomes. It appears that respondents did not view categorical grouping as influential with respect to maturity level grouping for improving process outcomes. It also appears that respondents did not perceive process grouping (according to maturity level) as being a contributor toward successful process outputs.

With respect to the survey's distributions, the study also showed the potential of bias with respect to the observed, received surveys versus the expected pattern of surveys. The potential of bias to affect the study must neither be discounted nor ignored. Given this notion, future studies may repeat the investigations herein to either corroborate or refute the current findings.

The final state of organizations that achieve and maintain the fifth maturity level reflects an optimized work setting in which wastefulness is minimized and productivity is enhanced. Similarly, improvements are observable regarding both efficiency and effectiveness within the organization. Given this notion, future studies may examine quantitatively the benefits of implementing process maturity as a process improvement framework. Specifically, future studies may investigate benefits with respect to cost savings, resource savings, and reduced time to generate products and services.

A variety of maturity models and quality management paradigms exist among disciplines that are unrelated to the software domain $[43,44,45]$. Future studies may also consider the efficacy of the model with respect to enhanced competitiveness organizationally. Such investigations may examine benchmarking ratios at different points in time to determine whether market competitiveness is enhanced as stages of the model are achieved progressively.

The preceding recommendations considered an internal perspective of the organization. Future studies may incorporate an external perspective of organizations that implement maturity modeling as a process improvement framework. For instance, as organizations progress through the stages of the maturity framework, customer service surveys may be performed to glean insight regarding perceptions of satisfaction. By doing so, organizations may judge whether improved customer service is perceived among market consumers as the organization achieves higher levels of process maturity through time.

Despite the existence of derivative adaptations of the maturity model framework among unrelated settings and disciplines that its origin, this study failed to show a complete portability across domains. However, as an initial study with biases and limitations, the current study provides a starting point from which future studies may be spawned.

\section{Acknowledgements}

This article was derived from the lead author's unpublished doctoral dissertation. Grateful thanks to Dr. Richard Gray, Dr. Mike Ewald, and Dr. Bobby Welch for their guidance during the conducting of this research.

\section{REFERENCES}

[1] R. Hutcherson. Organizational optimization. Authorhouse, Bloomington, 2014.

[2] D. Richter. Flash memories: Economic principles of performance, cost, and reliability optimization. Springer, New York, 2014.

[3] D. Doss, D. McElreath, C. Jensen, M. Wigginton, R. Goza, U. Becker, \& R. Roberts. Management and administration for criminal justice organizations. Kendall-Hunt, Dubuque, 2016.

[4] D. Doss, R. Henley, D. McElreath, B. Gokaraju, R. Goza, \& G. Lusk. Process improvement: Urban vs. rural personnel perspectives of a derivative CMMi process maturity framework. Proceedings of the Southwest Academy of Management, Vol. 2017, 44-51.

[5] D. Doss, R. Henley, D. McElreath, B. Gokaraju, S. Lin, G. Lusk, \& R. Goza. Managerial perspectives of the integrated capability maturity model among law enforcement personnel. Proceedings of the Southwest Academy of Management, Vol. 2017, 24-33.

[6] M. Atong \& T. Metz. Change or die: The business process improvement manual. CRC Press, Boca Raton, 2013. 
[7] P. Harmon. Business process change. Business process change. Morgan-Kaufman, Waltham, 2014.

[8] J. Von Brocke \& M. Rosemann (eds.). Handbook on business process management 2: Strategic alignment, governance, people, and culture. ( $2^{\text {nd }}$ ed.). Springer, New York, 2015.

[9] S. Mohapatra. Business process reengineering: Automation decision points in process reengineering. Springer, New York, 2013.

[10] N. Potter \& M. Sakry. Making process improvement work for service organizations: A concise action guide. Addison-Wesley, Upper Saddle River, 2012.

[11] J. Evans \& W. Lindsay. An introduction to Six Sigma and process improvement. ( $2^{\text {nd }}$ ed.). Cengage, Stamford, 2015.

[12] T. Hyötyläinen. Steps to improved firm performance with business process management: Adding business process management and its systems. New York, Springer, 2015.

[13] A. Arsanjani, N. Bharade, M. Borgenstrand, P. Schume, J. Wood, \& V. Zheltonogov. Business process management design guide: Using IBM business process manager. International Business Machines, Armonk, 2015.

[14] D. Ahern, A. Clouse, \& R. Turner. CMMII Distilled: A practical introduction to integrated process improvement. Pearson, Boston, 2008.

[15] A. Muras \& G. Goodnight. Process improvement \& performance management made simple: The FastTrack approach to getting results quickly. Bloomington, Xlibris, 2009.

[16] T. Boutros \& J. Cardella. The basics of process improvement. CRC Press, Boca Raton, 2016.

[17] S. Conger. Process mapping and management. Business Expert Press, New York, 2011.

[18] J. Persse. Process improvement essentials: CMMi, Six Sigma, and ISO 9001. O’Reilly Media, Sebastpool, 2006.

[19] D. Ajitabh. Global competitiveness, Excel Books, New Delhi, 2008.

[20] D.A. Doss. The Capability Maturity Model as a criminal justice process improvement paradigm. University of South Africa, Pretoria, 2014.

[21] D.A. Doss. An investigation of adapting the software capability maturity model architecture and framework within traditional industrial environments. Northcentral University, Prescott, 2004.

[22] D. Doss \& R. Kamery. A review of two improvement initiatives: business process improvement (BPI) and business process reengineering (BPR), Proceedings of the Academy of Educational Leadership, Vol. 11, No. 1, 95- 99.

[23] H.J. Harrington. Resource Management Excellence: The Art of Excelling in Resource and Assets Management, Paton Press, Chico, 2007.

[24] B. Curtis, W. Hefley, \& S. Miller. People CMM (2 ${ }^{\text {nd }}$ ed.). Pearson, Boston, 2010.

[25] D. Doss, I. Chen, \& L. Holland. A proposed variation of the capability maturity model framework among financial management settings, Proceedings of the Academy of Accounting and Financial Studies, Vol. 13, No. 1, 15-18.

[26] D. Doss \& R. Kamery. The Capability Maturity Model (CMM) architecture and framework within traditional industrial environments: An overview, Proceedings of the Academy of Educational Leadership, Vol. 11, No. 1, 101-105.

[27] D. Doss \& R. Kamery. The capability maturity model: A valid architecture to support a baseline environmental maturity model. Proceedings of the Academy of Information and Management Sciences, Vol. 9, No. 2, 1-5.

[28] D. Doss \& R. Kamery. A review of existing capability maturity model (CMM) derivative frameworks. Proceedings of the Academy of Educational Leadership, Vol. 11, No. 1, 125-130.

[29] J.R. Vacca. Computer and information security handbook. ( $2^{\text {nd }}$ ed.). Morgan Kauffman, Waltham, 2013.

[30] S. Caeiro, W. Filho, C. Jannour, U. Azeiteiro. Sustainability assessment tools in higher education institutions: Mapping trends and good practices around the world, Springer, New York, 2013.

[31] P. Charantimath. Total Quality Management (2 ${ }^{\text {nd }}$ ed.). Pearson, New Delhi, 2011.

[32] J. Crawford. Project management maturity model ( $3^{\text {rd }}$ ed.). CRC Press, Boca Raton, 2015.

[33] I. Burnstein. Practical software testing. Springer, New York, 2003.

[34] D. Doss \& R. Kamery. Implementation of the capability maturity model to support continuous process improvement tenets of the TQM philosophy. Proceedings of the Academy of Information and Management Sciences, Vol. 9, No. 2, $8-11$.

[35] Optimizing operational performance from a financial management perspective. Online available at: $\mathrm{http} / / /$ businessfinancemag.com/site-files/businessfinancemag .com/files/archive/businessfinancemag.com/files/misc_file $/ \mathrm{m}$ yDIALS_wp_financial.pdf

[36] D. Doss, W. Sumrall, D. McElreath, \& D. Jones. Economic and financial analysis for criminal justice organizations, CRC Press, Boca Raton, 2013.

[37] E. Brigham \& P. Daves. Intermediate financial management, Southwestern-Cengage, Mason, 2013.

[38] D. Doss, W. Sumrall, \& D. Jones. Strategic finance for criminal justice organizations, CRC Press, Boca Raton, 2012.

[39] P. Lacy \& J. Rutqvist. Waste to wealth: The circular economy advantage, Palgrave Macmillan, New York, 2015.

[40] J. Mishra \& A. Mohanty. Software engineering, Pearson, New Delhi, 2012.

[41] A. Allen, R. Henley, \& D. Doss. Vulnerability and resource dependency of nonprofit organizations in Alabama's Black Belt: Call for a better measure of perceived revenue diversification. Proceedings of the Association for Small Business and Entrepreneurship, Vol. 2014, 193-228.

[42] D. McNabb. Research methods for political science: Quantitative and qualitative approaches. M.E. Sharpe, Armonk, 2010. 
[43] D. Doss \& R. Kamery. Adapting the Capability Maturity Model (CMM) to unrelated industries as a process maturity framework. Proceedings of the Academy of Educational Leadership, Vol. 11, No. 1, 155-160.

[44] D. Doss \& R. Kamery. Exploring Total Quality Management (TQM) and derivative frameworks of the Capability Maturity Model (CMM). Proceedings of the Academy of Educational Leadership, Vol. 11, No. 1, 131-136.
[45] D. Doss \& R. Kamery. The software Capability Maturity Model architecture and potential applications to process improvements: Preliminary study. Proceedings of the Academy of Educational Leadership, Vol. 11, No. 1, 137-142.

[46] D. Doss \& R. Kamery. A review of Six-Sigma, International Organization for Standardization (ISO), and the Capability Maturity Model (CMM). Proceedings of the Academy of Educational Leadership, Vol. 11, No. 1, 119-124. 